DOI 10.15393/j9.art.2016.3767

УДК 821.161.1.09"1917/1992"

Екатерина Константиновна Агапитова

Петрозаводский государственный университет

(Петрозаводск, Российская Федерация)

ithaelin@mail.ru

\title{
ФОЯЬКЯОРНО-СКАЗОЧНАЯ ТРАДИЦИЯ В ТВОРЧЕСТВЕ И. А. ЕФРЕМОВА
}

Аннотация. В статье рассмотрены некоторые особенности поэтики волшебной сказки, нашедшие отражение в научно-фантастической литературе вообще и в творчестве И. А. Ефремова в частности. Известно, что главным героем фантастического произведения является собственно мир, созданный автором. Поэтому особое внимание уделено законам построения альтернативного фантастического мира, которые впервые были выделены исследователями (в том числе и Е. М. Неёловым) применительно к волшебной сказке: разделение на «свое» и «чужое», разграничение «взгляда извне» и «взгляда изнутри», отсутствие выбора, требование держать данное слово. В процессе анализа не только самого известного из творений И. А. Ефремова - романа «Туманность Андромеды», - но и других произведений писателя, был сделан вывод, что все эти законы нашли полное и явное отражение в поэтике его романов (причем не только научно-фантастических, но и исторических, например, в «Таис Афинской»).

Ключевые слова: И. А. Ефремов, научная фантастика, волшебная сказка, «свое»-«чужое», поэтика

C

удьба творческого наследия советского писателя-фантаста И. А. Ефремова была сложной и неоднозначной. Его творчество пользовалось огромной популярностью у читателей в 60-70 годы ХХ века (после выхода в свет в 1957 году известнейшего, можно сказать, программного романа «Туманность Андромеды», о котором мы до сих пор вспоминаем в первую очередь, когда слышим «Иван Ефремов»). В дальнейшем, после выхода в 1970 году романа «Час Быка», вызвавшего возмущение Ю. В. Андропова, наступил период замалчивания, даже запланированное издание собрание сочинений было отложено на несколько лет (и этот роман в него не вошел). Потом, после распада СССР, имя И. А. Ефремова было незаслуженно забыто и читателями, и критиками. И только сейчас, 
уже в XXI веке, его жизнь и деятельность вновь вызвали интерес у читателей и исследователей. По крайней мере, очень показательны даты выхода трех монографий, посвященных жизни писателя: «Через горы времени» Е. П. Брандиса и В. И. Дмитревского [5] - 1963 год, «Иван Антонович Ефремов» П. К. Чудинова [17] - 1987 год и «Иван Ефремов» О. Ерёминой и Н. Смирнова [8] - 2013 год.

Мы знаем И. А. Ефремова частично как писателя-фантаста («Туманность Андромеды», «Сердце Змеи», «Час Быка»), частично как автора исторических романов («Таис Афинская», «На краю Ойкумены»). При этом мы должны учитывать, что все особенности поэтики «Туманности Андромеды» точно так же можно найти в «Таис Афинской» и, наоборот, мир, описанный во всех его произведениях, един и живет по одним и тем же законам [2], [3]. С некоторой степенью условности можно рассуждать об определенной общности жанра всех его литературных произведений, особенно если учитывать то, что сам писатель неоднократно говорил, что все его произведения - фантастические, во всех есть фантастика и «фантазировать можно на любую тему - и о далеком будущем и о давно минувших временах» $[11,203]$. Таким образом, говоря о поэтике И. А. Ефремова, мы, в первую очередь, говорим о поэтике фантастического.

Во многом мир, созданный писателем, построен по законам поэтики волшебной сказки [13], [14]. В частности, самый бросающийся в глаза пример: в «Туманности Андромеды» возвращение земного звездолета «Тантра» из полета к погибшей планете представляет собой своеобразную инверсию сказочного пути «туда и обратно», о чем подробно рассказывается в книге Е. М. Неёлова «Волшебно-сказочные корни научной фантастики» [12]. И таких явных влияний достаточно много.

Поэтому, опираясь на предыдущие исследования, мы можем указать, что при создании альтернативного фантастического мира писатели используют (осознанно или нет) законы мира сказочного. Законов этих известно немного [14, 61-62]. Вопервых, это закон разделения на «свое» и «чужое». Вся территория мира равно для всех делится на «свое» - безопасное и «чужое» - крайне (даже смертельно) опасное. Во-вторых, это принципиальное отсутствие проблемы выбора. В этом 
мире не герой выбирает свою судьбу, а судьба - героя. B-третьих, это противопоставление взгляда «извне» и взгляда «изнутри». И именно это противопоставление создает так необходимую этому миру «иллюзию достоверности» $[2,134]$. И в-четвертых, это требование к героям держать данное слово, как бы мучительно это ни было, и какие бы неприятности это за собой ни влекло $[16,212]$, а также связанный с этим требованием феномен запрета (здесь и далее в тексте статьи, если не оговорено дополнительно, курсив мой. - E. А.) и естественное (для сказочного мира) его нарушение.

Начнем мы рассмотрение этих законов с противопоставления взгляда «извне» (с точки зрения читателя) и «изнутри» (с точки зрения героя), поскольку для самого мира и его поэтики этот закон наиболее важен. Взгляд «изнутри», от лица героя, из его времени и с учетом его психологии неоднократно отмечался исследователями как характерная особенность стиля И. А. Ефремова $[5,194],[6,172]$. Точно так же сам автор применительно к «Туманности Андромеды» напрямую писал в своей статье о творческой истории романа, что ему хотелось «взглянуть на мир завтрашнего дня не извне, а изнутри» (курсив И. А. Ефремова. - Е. А.) [9, 147]. При этом мы должны учитывать, что выразителем точки зрения автора всегда является главный положительный герой (а учитывая специфику творчества И. А. Ефремова с его явной нелюбовью к «злодеям», - просто главный герой), что при работающей у читателя «установке на вымысел» создает внутри фантастического мира полную «иллюзию достоверности». Это во многом связано с тем, как тщательно автор подбирал главного героя, который мог бы стать «аватарой» автора в его мире и носителем авторской идеи. О таких его размышлениях свидетельствует письмо фантаста к В. И. Дмитревскому о романе «Таис Афинская» от 25 мая 1971 года:

Мне нужно было взглянуть на деяния Александра глазами образованного, но не заинтересованного в политике, завоеваниях, торговле человека, свободного от принадлежности к той или иной школе философов, - философа, свободного от воспевания подвигов поэта, историка, не углубленного в свое творчество, как художник, и потому имеющего открытые глаза. Лучше гетеры не найти $[7,7]$. 
Взгляд изнутри требует предельной и безусловной реальности. Но эта внутренняя реальность возможна только в том случае, если есть граница, отделяющая фантастический мир от нашего обыденного физического мира $[14,59]$. Эта граница четко ощущается читателем, но прямо она проявляется исключительно редко (разве что в фантастическом произведении речь напрямую идет об ином мире - другая планета или параллельный мир). В творчестве И. А. Ефремова границей, «закрывающей» фантастический мир, служит, в первую очередь, время [3]. Время, отделяющее происходящие события от сегодняшней повседневности, поскольку прямой перелет на другую планету или просто покидание пределов Земли появляется только в «Часе Быка» и «Сердце Змеи» (в «Туманности Андромеды» для создания фантастического мира «земные» главы не менее важны, чем «космические», поэтому однозначно мы не можем включить ее в эту категорию). Мир «Туманности Андромеды» - это наш мир через полторы тысячи лет, и именно этот временной интервал и служит абсолютной границей. В принципе, И. А. Ефремов был не первым и не единственным, кто использовал такую временную границу; пожалуй, наиболее ярким примером подобного приема является «Машина времени» Г. Уэллса. Этим же способом пользовались и создатели исторических романов о совсем уж давно минувших временах - достаточно вспомнить Рони Старшего с его «Борьбой за огонь». Этот же прием временного отстранения И. А. Ефремов использовал и в своих исторических произведениях: 2300 лет отделяют нас от Таис и $4500-$ от Баурджеда, и эта толща лет не позволяет нам полностью признать их как персонажей «нашей» истории, хотя и Таис и, тем более, Александр Македонский - реальные исторические личности.

Закон разделения на «свое» и «чужое» также необычайно важен для понимания структуры мира ефремовской фантастики [1]. В творчестве И. А. Ефремова мы видим своеобразную эволюцию сказочного противопоставления «своего» и «чужого» - от полнейшего неприятия и борьбы в исторических произведениях до заведомого «приятия» в романах о будущем. Причем даже в так называемых исторических романах намечен уже путь постепенного «освоения» чужого, которое достигает своего максимума в романе «Час Быка». Вся 
прописанная в этом романе хронология ефремовского мира очень четко обозначает вехи этого «освоения», все больше увеличивая общность и единение мира: Эра Разобщенного Мира Эра мирового Воссоединения - Эра Общего Труда - Эра Встретившихся Рук. Причем последняя точка на самом деле последней не является, так как главная героиня, Фай Родис, дочь Эры Встретившихся Рук, уже задумывается о том, что придет ей на смену в грядущем:

Эра соединения Шакти и Тамаса? Уравновешивание корней двухполюсной вселенной? Но как избежать замыкания, бесструктурности, аннигиляции? ${ }^{1}$

Эта фраза любимой героини И. А. Ефремова на новом уровне дает нам понимание необходимости для созданного мира (для реального, впрочем, тоже) как минимум двух начал - «своего» и «чужого», но при этом борьба их не является обязательным элементом: в конце концов в магните полюса не враждуют друг с другом, но их наличие обеспечивает существование магнитного поля, то есть, пользуясь этой аналогией, - мира.

Закон «отсутствие выбора» и требование «держать данное слово» можно считать наиболее интересными для исследования уже героев произведений и действий, которые они совершают, поскольку эти два закона напрямую отражаются не только на фантастическом мире, но и на психологии героев, его населяющих. Иногда данное слово заменяет выбор и объясняет его отсутствие, поэтому и рассматривать их удобнее вместе. Проще всего заметить это «отсутствие выбора» на примере путешествия героя, которое он выбирает не сам, что заметили не только исследователи $[15,57-58]$, но и авторы фантастических произведений. Путешествие присутствует во всех романах И. А. Ефремова, и во всех случаях оно не является добровольным: в лучшем случае - это сознательное выполнение долга. «Наш долг заставил отдать тридцать седьмую экспедицию для Великого Кольца», - говорит командир экспедиции в «Туманности Андромеды» (III, 263). Во всех же остальных случаях: отправлен приказом Фараона искать сказочный Пунт Баурджед («Путешествие Баурджеда»), отправлен в командировку в Индию Гирин («Лезвие бритвы»). 
Спартанка Эгесихора нарушает законы Афин и вынуждена бежать от суда в Египет; вместе с ней уезжает Таис, давшая ей слово («Таис Афинская»). Захвачен в плен пиратами Пандион, выкинут за борт во время шторма у берегов Египта, бежит из египетского плена через половину Африки к соплеменникам друга, которые только и могут помочь ему вернуться на родину («На краю Ойкумены»). Экипаж звездолета «Темное пламя» отправлен с заданием на Торманс («Час Быка»). Таким образом, все путешествия в мире И. А. Ефремова можно соотнести либо со сказочными «путешествием по заданию царя», либо с путешествием «куда глаза глядят», чтобы успокоилась душа героя и вернулась нарушенная целостность в мир. Именно так, через путешествие в Индию, пытаются найти лекарство от амнезии Леа герои «Лезвия бритвы». В то же время в романе «Час Быка» три звездолета предков тормансиан, утративших надежду на спасение планеты, убегают с Земли в сторону только что открытого скопления темной материи недалеко от Солнца - типичнейшее «куда глаза глядят».

Последний закон «держать данное слово» особенно важен, так как отражает авторскую точку зрения. По воспоминаниям М. Ф. Лукьяновой, «пуще всего Иван Антонович не терпел неправды» $[4,21]$, и этим своим свойством писатель наделил многих своих героев. Таким образом, персонаж, который является носителем авторской идеи, никогда не врет, что приводит к своеобразной маркированности «правдой» положительного героя. Исключением из этого правила не является даже спектакль, разыгранный Фай Родис в «Часе Быка», так как изначально главной героиней этого романа должна была стать Чеди Даан [10, 457], и именно она тяжелее всех переживала этот обман. Поэтому первое, что пытаются выяснить герои Ефремова, - какова степень правдивости собеседника. Если случается нарушение правила «говорить правду», то расплата неизбежна, что понятно из волшебно-сказочной логики: после нарушения запрета неминуемо следует наказание. Можно сказать, пользуясь мифолого-этнографическими аналогиями, что на всех героев И. А. Ефремова наложен гейс «говорить правду». И в случае нарушения запрета происходит то же самое, что с классическими мифологическими героями. Это наглядно демонстрирует история звездолета «Темное Пламя», где пятеро из тринадцати членов экипажа погибают, 
причем погибают, так или иначе, в результате обмана (своего или чужого). В частности Фай Родис в самом начале обманывает Чойо Чагаса, инсценировав разговор с Землей и якобы вызвав второй звездолет на подмогу, когда же Вир Норин рассказывает тормансианским ученым о структуре Вселенной, один из них делает совершенно правильный вывод о безмерной удаленности Земли и об обмане; в итоге к Фай Родис приходят убийцы, впрочем, и сам горе-ученый погибает из-за предательства - вместо обещанной награды он получает выстрел в затылок $(\mathrm{V}, 2,433)$. А до этого, когда Тивиса, Тор Лик и Ген Атал, после того как у них разрядились батареи в роботах-охранниках, просят помощи, чтобы выбраться из дикого района, занятого бандитами, Чойо Чагас сознательно обманывает Фай Родис, которая в результате невольно обманывает своих друзей. В итоге помощь приходит слишком поздно.

Правдивость героев напрямую связана с требованием «соблюдать инструкции», то есть не нарушать запрет. Такое нарушение, как и в сказке, ввергает героев в неприятности и становится необходимым двигателем волшебно-сказочного сюжета. В «Туманности Андромеды» молодые астронавигаторы нарушают инструкцию и прямой приказ командира корабля разбудить его, когда корабль будет проходить неизученный район. В результате корабль попадает в поле притяжения Железной звезды. Другим показательным примером является ситуация с Мвеном Масом в «земных» главах этого же романа. Ему хочется самому поставить грандиозный эксперимент, не просчитав до конца риски, в обход прямого запрета Совета. В результате уничтожен спутник с группой добровольцев и едва не погиб гениальный ученый Рен Боз, который впоследствии (по результатам этого эксперимента) обеспечит создание звездолетов нового типа, помогающих достигнуть любого конца галактики за вполне обозримое время в пути. Сам же Мвен Мас обрекает себя на общественную смерть на острове Забвения (которая, впрочем, едва не стала физической после его встречи с тигром). В творчестве И. А. Ефремова схема запрета и его нарушения используется довольно часто, и всегда за нарушением запрета следует какоелибо «приключение». Например, в «Таис Афинской» героиня не смогла сдержать эллинского пренебрежения к другим 
культурам и неуважительно отозвалась о звероподобных египетских богах (хотя и знала, что этого делать не следует нарушила запрет), за что и попала к крокодилам. Затем она вполне сознательно нарушает приказ Александра Македонского - никаких гражданских во время марша к Персеполису, в результате столица Ахеменидов сожжена рукой греческой гетеры, а сама она едва не поссорилась с великим полководцем. В любом случае, на этом закончилось ее участие в персидском походе - в индийский она уже не пошла. Таким образом, можно сказать, что после нарушения этого запрета умерла Таис - сумасшедшая девчонка и родилась Таис - мудрая подруга Птолемея. Таким образом, ничем психологически не обоснованный сказочный запрет в творчестве И. А. Ефремова трансформируется или в приказ вышестоящего руководства (Александр Македонский, совет Звездоплавания, командир корабля) или во внутреннее психологическое чувство правильного (у Таис), но его нарушение однозначно запускает цепочку приключений, описанную еще В. Я. Проппом.

Все сказанное позволяет прийти к выводу, что закрытость волшебно-сказочного мира с его разделением на «свое» и «чужое» и обязательное наличие запрета (и, как следствие, неминуемое его нарушение) не просто присутствуют в литературном мире И. А. Ефремова, но являются необходимым элементом его поэтики, без которого мы не сможем понять все нюансы сюжета. Причем эти законы волшебно-сказочной поэтики, на основе которых строится любой альтернативный фантастический мир, четко прослеживаются во всем объеме творчества И. А. Ефремова от его исторических повестей, через центральный философский роман «Лезвие бритвы», до космической трилогии «Туманность Андромеды» - «Сердце Змеи» — «Час Быка».

\section{Примечания}

Ефремов И. А. Собрание сочинений: в 5 т. М.: Молодая гвардия, 1986-1989. Т. 5. Кн. 2. С. 50. Далее ссылки на это издание приводятся в тексте статьи с указанием номера тома римской цифрой, книги арабской в круглых скобках. 


\section{Список литературы}

1. Агапитова Е. К. Оппозиция «свое/чужое» в творчестве И. А. Ефремова // «Свое» и «чужое» в культуре народов европейского Севера: материалы 4-ой международной научной конференции / отв. ред. В. М. Пивоев. - Петрозаводск: Изд-во ПетрГУ, 2003. - С. 115-118.

2. Агапитова Е. К. О фольклоризме романа И. А. Ефремова «Туманность Андромеды» // Проблемы детской литературы и фольклор. - Петрозаводск: Изд-во ПетрГУ, 2004. - С. 132-139.

3. Агапитова Е. К. Проблема времени в творчестве И. А. Ефремова // Проблемы детской литературы и фольклор. - Петрозаводск: Изд-во ПетрГУ, 2004. - С. 122-131.

4. Ахметов С. Ф. Рядом с Ефремовым // Уральский следопыт. - 1996. № 8-9. - С. 19-26.

5. Брандис Е. П., Дмитревский В. И. Через горы времени. Очерк творчества И. Ефремова. - М.; Л.: Советский писатель, 1963. - 200 с.

6. Брандис Е. П., Дмитревский В. И. Реальность фантастики (О литературном творчестве И. А. Ефремова) // Нева. — 1972. — № 4. - С. 167-174.

7. Дымов Ф. Кораблю - взлёт! Из переписки И. А. Ефремова // Книжное обозрение. — № 7 (1133). - 12 февраля 1988 г. - С. 7-10.

8. Ерёмина О. А., Смирнов Н. Иван Ефремов. - М.: Молодая гвардия, 2013. - 686 с.: ил. (Жизнь замечательных людей: сер. биогр.; вып. 1440).

9. Ефремов И. А. На пути к роману «Туманность Андромеды» // Вопросы литературы. - 1961. - № 4. - С. 142-153.

10. Ефремов И. А. Как создавался «Час быка» (Беседа с Иваном Антоновичем) [записал Г. Савченко] // Ефремов И. А. Собр. соч.: в 5 т. - М.: Молодая гвардия, 1986-1989. - Т. 5. - Кн. 2. - С. 454-460.

11. Материалы к творческой биографии И. А. Ефремова. Жизнь ученого и писателя. Интервью с И. Ефремовым // Вопросы литературы. 1978. - № 2. — С. 187-208.

12. Неёлов Е. М. Волшебно-сказочные корни научной фантастики. - Л.: Изд-во ЛГУ, 1986. - 200 с.

13. Неёлов Е. М. Сказка, фантастика, современность. - Петрозаводск: Карелия, 1987. - 126 с.

14. Неёлов Е. М. Фантастический мир как категория исторической поэтики (статья вторая: проблема границ) // Проблемы исторической поэтики: сб. науч. тр. - Петрозаводск: Изд-во ПетрГУ, 1992. - Вып. 2: Художественные и научные категории. - С. 58-66.

15. Неёлов Е. М., Струкова А. Е. Русская фантастика: нерешенные проблемы. - Петрозаводск: Изд-во ПетрГУ, 2013. - 71 с.

16. Толкин Д. Р. Р. О волшебных историях // Толкиен Дж. Возвращение Беорхтнота и другие произведения. - М.: ЭКСМО-Пресс; СПб.: Terra fantastica, 2001. - С. 135-230.

17. Чудинов П. К. Иван Антонович Ефремов (1907-1972). - М.: Наука, 1987. -224 c. 
Ekaterina K. Agapitova

Petrozavodsk State University

(Petrozavodsk, Russian Federation)

ithaelin@mail.ru

\title{
FOLKLORE AND FAIRY TALE TRADITION IN I. A. EFREMOV'S WORKS
}

\begin{abstract}
In the article the author studies some features of poetics of a fairy tale which found reflection in science fiction literature in general and in I. A. Efremov's works in particular. It is well-known fact that the main hero of a fantastic work is the world itself created by the author. Therefore, special attention is paid to laws of creation of an alternative fantastic world which were for the first time allocated by researchers (and by E. M. Neyolov too) in relation to the fairy tale: division into "one's own" and "someone else's", distinction between "a look from outside" and "a look from inside", the lack of choice, the requirement to keep a given word. In the course of the analysis of I. A. Efremov's creations (the world-known novel "The Nebula of Andromeda" and other his works) there was made a conclusion that all these laws found their full and obvious reflection in the poetics of his novels (not only in science fiction but in historical novels too, for example "Tais Afinskaya").
\end{abstract}

Keywords: I. A. Efremov, science fiction, magic fairy tale, poetics

\section{References}

1. Agapitova E. K. Oppozitsiya «svoe/chuzhoe» v tvorchestve I. A. Efremova [The Opposition "Own's Own/Someone Else's" in the Works of I. A. Efremov]. «Svoe» $i$ «chuzhoe» $v$ kul'ture narodov evropeyskogo Severa: Materialy 4-oy mezhdunarodnoy nauchnoy konferentsii ["Own's Own" and "Someone Else's" in Culture of the People of the European North: the Proceedings of the Fourth International Scientific Conference]. Petrozavodsk, Petrozavodsk State University Publ., 2003, pp. 115-118.

2. Agapitova E. K. O fol'klorizme romana I. A. Efremova «Tumannost' Andromedy» [About Folklorism of the Novel of I. A. Efremov "The Nebula of Andromeda"]. Problemy detskoy literatury i fol'klor [The Problems of Children's Literature and Folklore: Collection of Scientific Works]. Petrozavodsk, Petrozavodsk State University Publ., 2004, pp. 132-139.

3. Agapitova E. K. Problema vremeni v tvorchestve I. A. Efremova [The problems of time in the works of I. A. Efremov]. Problemy detskoy literatury i fol'klor [The Problems of Children's Literature and Folklore: Collection of Scientific Works]. Petrozavodsk, Petrozavodsk State University Publ., 2004, pp. 122-131.

4. Akhmetov S. F. Ryadom s Efremovym [Close by Efremov]. Uralskiy sledopyt [Ural Pathfinder], 1996, no. 9, pp. 19-26.

5. Brandis E. P., Dmitrevskiy V. I. Cherez gory vremeni. Ocherk tvorchestva I. Efremova [Through the Mountains of Times. A Review on Ivan Efremov's Literary Works]. Moscow, Leningrad, Sovetskiy pisatel' Publ., 1963. 200 p. 
6. Brandis E. P., Dmitrevskiy V. I. Real'nost' fantastiki (O literaturnom tvorchestve I. A. Efremova) [Reality of The Fantastika (About Literary Works of I. A. Efremov)]. Neva, 1972, no. 4, pp. 167-174.

7. Dymov F. Korablyu — vzlet! Iz perepiski I. A. Efremova [Spaceship - Takeoff! From I. A. Efremov's Correspondence]. Knizhnoe obozrenie, 1988, no. 7 (1133), 12 February, pp. 7-10.

8. Eremina O. A., Smirnov N. N. Ivan Efremov. Moscow, Molodaya gvardiya Publ., 2013. 686 p. (Life of Distinguished People: Biographical Series; edition 1440).

9. Efremov I. A. Na puti k romanu «Tumannost' Andromedy» [On the Way Toward the Novel "The Nebula of Andromeda"]. Voprosy literatury, 1961, no. 4, pp. $142-153$.

10. Efremov I. A. Kak sozdavalsya "Chas byka» (Beseda s Ivanom Antonovichem) [How "The Bull's Hour" Was Created (The Conversation with Ivan Efremov)]. Efremov I. A. Sobranie sochineniy: $v 5$ tomakh [Efremov I. A. The Collected Works: in 5 Vols]. Moscow, Molodaya gvardiya Publ., 1986-1989, vol. 5, part 2, pp. 454-460.

11. Materialy k tvorcheskoy biografii I. A. Efremova. Zhizn' uchenogo i pisatelya [Materials for Ivan Efremov's Biography. Life of a Scientist and Writer]. Voprosy literatury, 1978, no. 2, pp. 187-208.

12. Neyolov E. M. Volshebno-skazochnye korni nauchnoy fantastiki [The Magical Fairy Tale Roots of Science Fiction]. Leningrad, Leningrad State University Publ., 1986. 200 p.

13. Neyolov E. M. Skazka, fantastika, sovremennost' [Fairy Tale, Science Fiction, Modernity]. Petrozavodsk, Karelia Publ., 1987. 126 p.

14. Neyolov E. M. Fantasticheskiy mir kak kategoriya istoricheskoy poetiki (stat'ya vtoraya: problema granits) [The Fantastic World as a Category of Historical Poetics (Article No. 2: The Problem of the Boundaries)]. Problemy istoricheskoy poetiki [The Problems of Historical Poetics]. Petrozavodsk, Petrozavodsk State University Publ., 1992, vol. 2: Artistic and Scientific Categories, pp. 58-66.

15. Neyolov E. M., Strukova A. E. Russkaya fantastika: nereshennye problemy [The Russian Fantastika: Unresolved Problems]. Petrozavodsk, Petrozavodsk State University Publ., 2013. 71 p.

16. Tolkien J. R. R. O volshebnykh istoriyakh [On Fairy Stories]. Tolkien J. R. R. Vozvrashchenie Beorkhtnota i drugie proizvedeniya [The Homecoming of Beorhtnoth Beorhthelm's Son and Another Works]. Moscow, EKSMO-Press Publ.; St. Petersburg, Terra fantastica Publ., 2001, pp. 135-230.

17. Chudinov P. K. Ivan Antonovich Efremov (1907-1972). Moscow, Nauka Publ., 1987. 224 p. 